\title{
KELAS RAMSEY MINIMAL UNTUK PASANGAN GRAF MATCHING DAN DUA GRAF LENGKAP
}

\author{
NAILUL YUNI PERMATAPUTRI, LYRA YULIANTI, NARWEN \\ Program Studi S1 Matematika, \\ Fakultas Matematika dan Ilmu Pengetahuan Alam, Universitas Andalas, \\ Kampus UNAND Limau Manis Padang, Indonesia. \\ email : nailuyuni@gmail.com
}

Diterima 22 Juni 2019 Direvisi 6 Juli 2019 Dipublikasikan 4 Agustus 2019

\begin{abstract}
Abstrak. Misalkan diberikan graf $G$ dan $H$ sebarang. Notasi $F \rightarrow(G, H)$ menyatakan bahwa terdapat sebarang pewarnaan merah-biru terhadap sisi-sisi graf $F$ mengakibatkan $F$ memuat subgraf merah graf $G$ atau subgraf biru graf $H$. Kemudian, notasi $F * \nrightarrow$ $(G, H)$ menyatakan bahwa terdapat pewarnaan merah-biru terhadap sisi-sisi di graf $F *$ $\nrightarrow(G, H)$ sehingga $F *$ tidak memuat graf $G$ merah dan graf $H$ biru. Graf $F$ dikatakan sebagai graf Ramsey $(G, H)$-minimal jika (1) $F \rightarrow(G, H)$, dan $(2) \forall e \in F, F *=F \backslash\{e\}$, $F * \nrightarrow(G, H)$. Pada penelitian ini akan dicari graf yang termasuk dalam kelas Ramsey minimal $\mathcal{R}\left(m K_{2}, 2 K_{n}\right)$, untuk beberapa nilai $n \geq 3$ dan $m \geq 2$.
\end{abstract}

Kata Kunci: Graf lengkap, Graf Ramsey Minimal, Matching

\section{Pendahuluan}

Kombinatorika adalah salah satu bidang dalam ilmu matematika. Dalam penelitian ini akan dikaji salah satu kajian dalam bidang kombinatorika yaitu teori graf. Teori graf merupakan cabang kajian ilmu yang mempelajari sifat-sifat graf. Graf $G$ adalah pasangan terurut $(V(G), E(G))$ dengan $V(G)$ merupakan himpunan titik-titik yang tidak kosong dan $E(G)$ merupakan himpunan sisi-sisi.

Teori Ramsey merupakan salah satu cabang teori dalam teori graf yang sedang banyak diteliti. Misalkan diberikan graf $G$ dan $H$ sebarang. Notasi $F \rightarrow(G, H)$ menyatakan bahwa terdapat sebarang pewarnaan merah-biru terhadap $F$ sehingga $F$ memuat graf $G$ merah atau memuat graf $H$ biru. Selanjutnya, notasi $F \nrightarrow(G, H)$ menyatakan bahwa $F$ tidak memuat $G$ merah dan $F$ tidak memuat $H$ biru. Jika graf $F$ memenuhi $F \rightarrow(G, H)$ dan $F \backslash\{e\}$ memenuhi $F \backslash\{e\} \nrightarrow(G, H) \forall e \in E(F)$, maka $F$ termasuk ke dalam kelas Ramsey $(G, H)$-minimal, dinotasikan $\mathcal{R}(G, H)$.

Graf lengkap $K_{n}$ adalah graf terhubung dengan $n$ titik dimana setiap titiknya bertetangga dan setiap titik memiliki derajat $n-1$. Dalam penelitian ini akan dikaji tentang penentuan kelas Ramsey minimal untuk pasangan graf $m K_{2}$ dan $2 K_{n}$, untuk beberapa nilai $n \geq 3$ dan $m \geq 2$.

Pada tahun 2016, Wijaya dan Baskoro menemukan cara mengkonstruksi suatu graf yang termasuk ke dalam kelas $\mathcal{R}\left(2 K_{2}, 2 H\right)$, dimana graf $H$ adalah su- 
atu graf lintasan, graf siklus atau graf bintang [3]. Kemudian Wijaya dkk juga melakukan penelitian pada tahun yang sama untuk graf yang termasuk kedalam kelas $\mathcal{R}\left(m K_{2}, H\right)$, dimana $H$ adalah graf sebarang. Lalu diberikan syarat perlu dan syarat cukup untuk graf yang termasuk ke dalam kelas $\mathcal{R}\left(m K_{2}, H\right)$ untuk graf $H$ sebarang, dimana $m$ adalah bilangan bulat positif [4]. Pada tahun 2018, Yulianti dan Nazra memberikan karakterisasi graf $F$ yang termasuk dalam kelas $\mathcal{R}\left(3 K_{2}, 2 C_{n}\right)$ untuk $n \geq 3$ serta beberapa graf yang termasuk ke dalam kelas $\mathcal{R}\left(3 K_{2}, 2 C_{3}\right)$ [5].

Graf $m K_{2}$ (matching) adalah $m$ buah graf lengkap dengan 2 titik dan graf $2 K_{n}$ merupakan graf lengkap dengan $n$ titik sebanyak 2 buah. Pada penelitian ini akan dicari graf yang termasuk dalam kelas Ramsey minimal $\mathcal{R}\left(m K_{2}, 2 K_{n}\right)$, untuk beberapa nilai $n \geq 3$ dan $m \geq 2$.

\section{Landasan Teori}

Definisi 2.1. [1] Suatu graf $G$ adalah pasangan himpunan terurut $G=$ $(V(G), E(G))$ yang terdiri dari $V(G)$ merupakan himpunan titik-titik yang tidak kosong dan $E(G)$ merupakan himpunan sisi.

Suatu jalan (walk) pada graf $G$ adalah suatu barisan tak kosong $W=v_{0}, e_{1}, v_{1}, e_{2}, \ldots, e_{k}, v_{k}$ dimana titik dan sisinya boleh berulang, sedemikian sehingga, $1 \leq i \leq k$ ujung dari $e_{i}$ adalah $v_{i-1}$ dan $v_{i}$.Jalur (trail) adalah suatu jalan yang melewati setiap sisi yang berbeda. Lintasan (path) adalah suatu jalan yang melewati sisi dan titik yang berbeda[1].

Suatu graf $G$ dikatakan graf terhubung jika untuk setiap dua titik di $G$ terdapat lintasan di $G$ yang menghubungkan kedua titik tersebut, sedangkan suatu graf $G$ dikatakan graf tidak terhubung jika terdapat dua titik di $G$ yang tidak memiliki lintasan yang menghubungkan kedua titik tersebut. Graf yang hanya memiliki satu titik disebut graf trivial, sebaliknya jika graf tersebut memiliki lebih dari satu titik disebut graf non trivial [1].

Suatu graf $H$ dikatakan subgraf dari graf $G$ apabila $V(H) \subseteq V(G)$ dan $E(H) \subseteq$ $E(G)$. Gambar 1 adalah contoh dari subgraf. Komponen adalah subgraf terhubung maksimal. Jumlah komponen adalah banyaknya subgraf terhubung maksimal. Graf sederhana adalah suatu graf yang tidak memuat loop dan sisi ganda, dimana Loop merupakan sisi yang mempunyai titik ujung yang sama dan jika dua buah titik dihubungkan oleh dua atau lebih sisi disebut sisi ganda. Suatu matching $M$ di graf $G$ adalah subgraf dari $G$, sedemikian sehingga sisi-sisi di $M$ adalah sisi-sisi yang saling lepas di $G$.

Gabungan dua graf $G$ dan $H$ yang dinotasikan dengan $G \cup H$ adalah gabungan himpunan sisi $G$ dan $H$ dan gabungan himpunan titik $G$ dan $H$. Gambar 1 (c) merupakan contoh dari gabungan graf $K_{3}$ dan graf $K_{4}$ [1].

Graf siklus dinotasikan dengan $C_{n}$ adalah graf terhubung dengan $n$ titik dimana setiap titiknya berderajat 2 . Graf bintang dinotasikan dengan $K_{1, n}$ adalah graf terhubung dengan satu titik berderajat $n$ dan $n$ titik berderajat 1 . Graf lengkap dinotasikan dengan $K_{n}$ adalah graf terhubung dengan $n$ titik dimana setiap titik bertetangga dan setiap titik memiliki derajat $n-1$. Derajat merupakan banyak sisi yang terkait pada suatu titik [1]. Gambar 2 merupakan contoh 


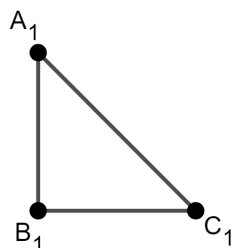

(a). $K_{3}$

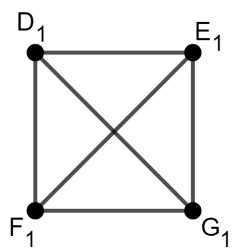

(b). $\mathrm{K}_{4}$

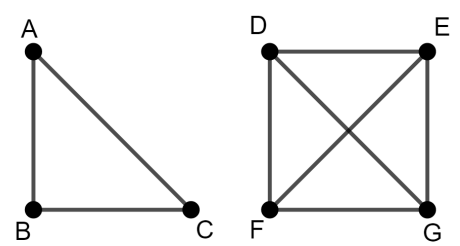

(c). $K_{3} \cup K_{4}$

Gambar 1. Graf $K_{3}$ adalah subgraf dari graf $K_{4}$

graf lengkap dengan $n=6$.

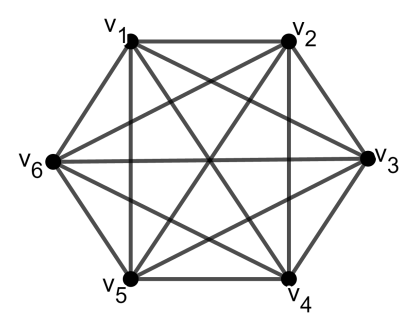

Gambar 2. Graf $K_{6}$

Misalkan diberikan graf $G$ dan $H$ sebarang. Notasi $F \rightarrow(G, H)$ menyatakan bahwa terdapat sebarang pewarnaan merah-biru terhadap sisi-sisi graf $F$ mengakibatkan $F$ memuat subgraf merah graf $G$ atau subgraf biru graf $H$. Kemudian, notasi $F * \nrightarrow(G, H)$ menyatakan bahwa terdapat pewarnaan merah-biru terhadap sisi-sisi di graf $F * \nrightarrow(G, H)$ sehingga $F *$ tidak memuat graf $G$ merah dan graf $H$ biru [2].

Definisi 2.2. [2] Diberikan graf $G$ dan $H$ sebarang. Graf $F$ dikatakan sebagai graf Ramsey $(G, H)$-minimal jika :

(1) $1 . F \rightarrow(G, H)$

(2) 2. $\forall e \in F, F *=F \backslash e, F * \nrightarrow(G, H)$

Kelas yang berisikan semua $\mathrm{F}$ yang memenuhi (1) dan (2) dinamakan kelas Ramsey $(G, H)$-minimal, dinotasikan dengan $\mathcal{R}(G, H)$.

\section{Pembahasan}

Pada bagian ini akan diberikan graf yang menjadi anggota kelas Ramsey minimal untuk pasangan graf $4 K_{2}$ dan graf $2 K_{7}$.

Teorema 3.1. Jika terdapat graf $4 K_{2}$ dan graf $2 K_{7}$, maka diperoleh bahwa graf $2 K_{13} \in \mathcal{R}\left(4 K_{2}, 2 K_{7}\right)$. 
Bukti. Akan dibuktikan $2 K_{13} \rightarrow\left(4 K_{2}, 2 K_{7}\right)$. Pandang sebarang pewarnaan merah-biru terhadap sisi-sisi $2 K_{13}$. Pertama, andaikan terdapat $4 K_{2}$ merah, maka pembuktian selesai. Selanjutnya misalkan tidak terdapat $4 K_{2}$ merah dalam pewarnaan tersebut, maka subgraf merahnya berbentuk $3 C_{3}, 3 K_{1,12}, K_{1,12} \cup 2 C_{3}$, $2 K_{1,12} \cup C_{3}$, atau $K_{7}$. Untuk kemungkinan $3 C_{3}$ jika sebarang sisi pada $2 K_{13}$ diwarnai dengan warna merah hingga membentuk $3 C_{3}$, maka sisi-sisi yang tersisa diwarnai biru, dan akan selalu memuat $2 K_{7}$ biru yang berada di dua komponen berbeda.

Selanjutnya jika sebarang sisi pada graf $2 K_{13}$ diwarnai dengan warna merah hingga subgraf merah berbentuk $3 K_{1,12}$, maka sisi-sisi yang tersisa diwarnai biru. Sisi-sisi tersebut selalu memuat $2 K_{7}$ biru yang berada di dua komponen berbeda. Kemudian untuk kemungkinan $K_{1,12} \cup 2 C_{3}$, jika sebarang sisi diwarnai merah hingga membentuk $K_{1,12} \cup 2 C_{3}$, maka sisi-sisi yang tersisa diwarnai biru, dan akan selalu memuat $2 K_{7}$ biru, dimana $2 K_{7}$ nya berada di dua komponen berbeda. Selanjutnya jika sebarang sisi diwarnai merah hingga subgraf merah berbentuk $2 K_{1,12} \cup C_{3}$, maka sisi-sisi yang tersisa diwarnai biru, dan akan selalu memuat $2 K_{7}$ biru yang berada di dua komponen berbeda. Kemudian untuk kemungkinan terakhir $K_{7}$, jika sebarang sisi diwarnai merah hingga membentuk $K_{7}$, maka sisa grafnya $K_{7}$ pada graf yang diwarnai $K_{7}$ merah dan $K_{13}$ pada komponen berbeda. Dari sisa graf tersebut selalu bisa diwarnai $2 K_{7}$ biru. Untuk semua kemungkinan pewarnaan diatas, selalu didapatkan $2 K_{n}$ biru sehingga terbukti bahwa $2 K_{13} \rightarrow\left(4 K_{2}, 2 K_{7}\right)$. Pada Gambar 3 diberikan salah satu contoh pewarnaannya.
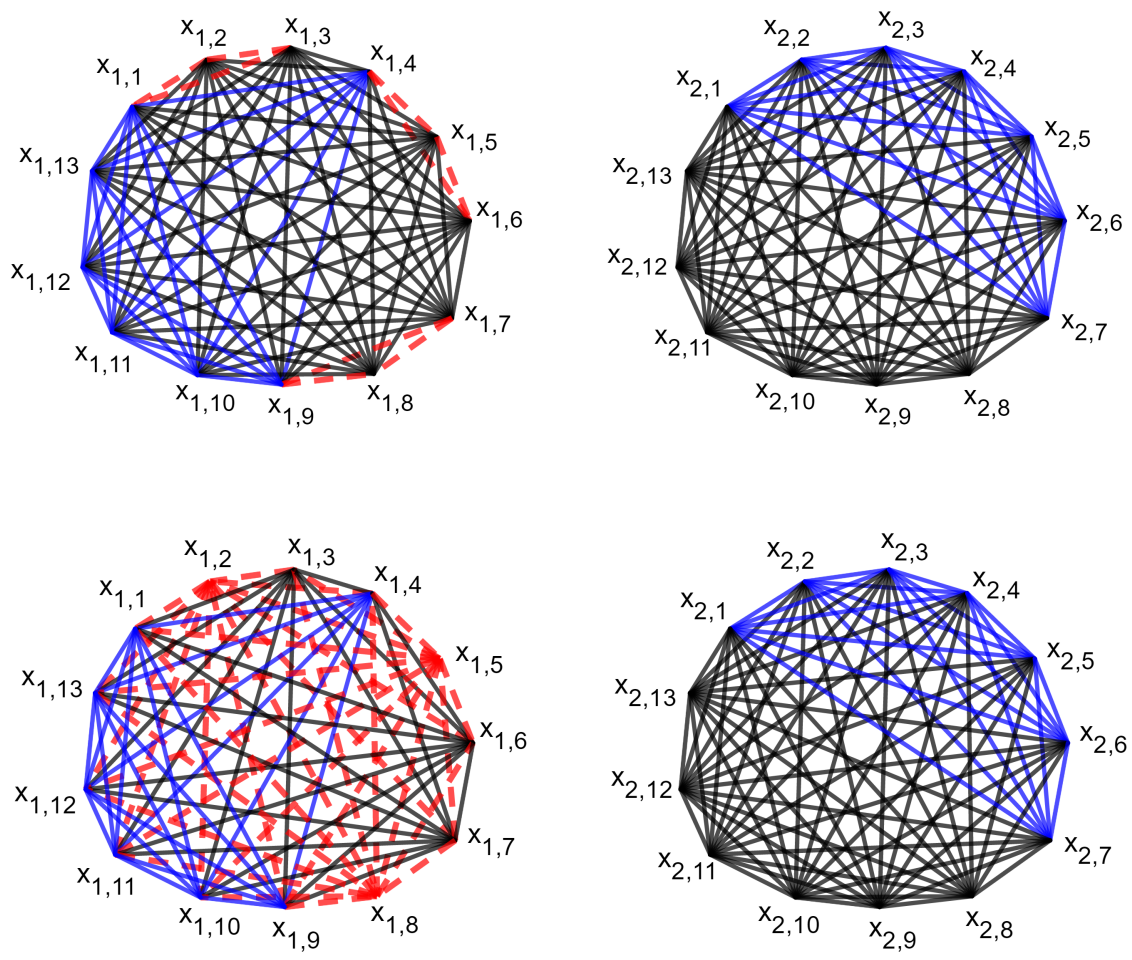

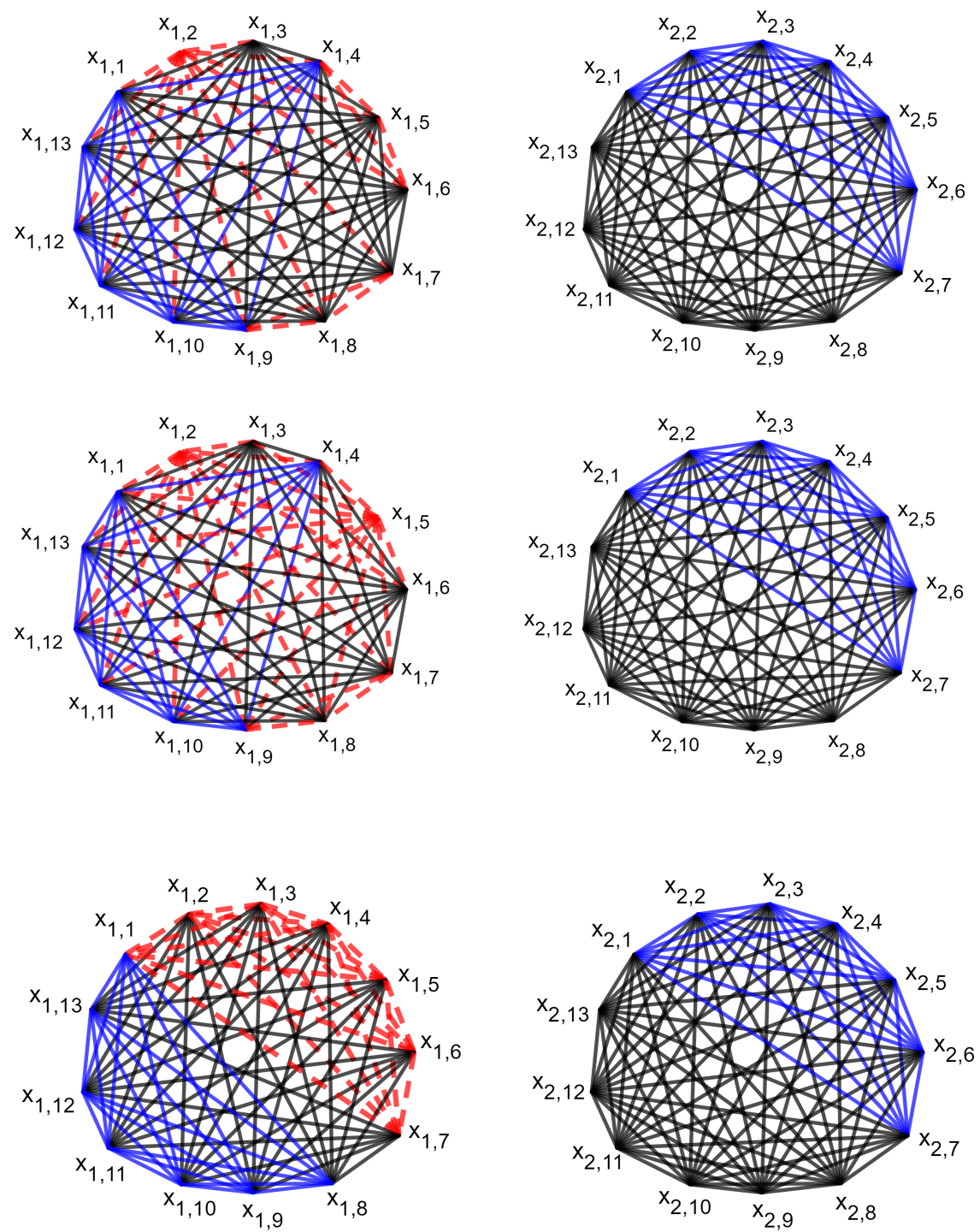

Gambar $3.2 K_{13} \rightarrow\left(4 K_{2}, 2 K_{7}\right)$

Kedua, akan ditunjukkan bahwa $2 K_{13} \backslash e \nrightarrow\left(4 K_{2}, 2 K_{7}\right) \forall e \in E\left(2 K_{13}\right)$. Saat dihapus satu sisi pada graf $2 K_{13}$, lakukan pewarnaan dengan cara mewarnai merah pada graf $K_{13}$ pertama yang sisinya dihapus dengan warna merah sehingga tidak diperoleh $2 K_{7}$ biru seperti pada Gambar 4 Jadi, terbukti bahwa $2 K_{13} \backslash e \nrightarrow\left(4 K_{2}, 2 K_{7}\right)$.

Pada bagian ini akan diberikan graf yang menjadi anggota kelas Ramsey minimal untuk pasangan graf $4 K_{2}$ dan graf $2 K_{8}$.

Teorema 3.2. Jika terdapat graf $4 K_{2}$ dan graf $2 K_{8}$, maka diperoleh bahwa graf 

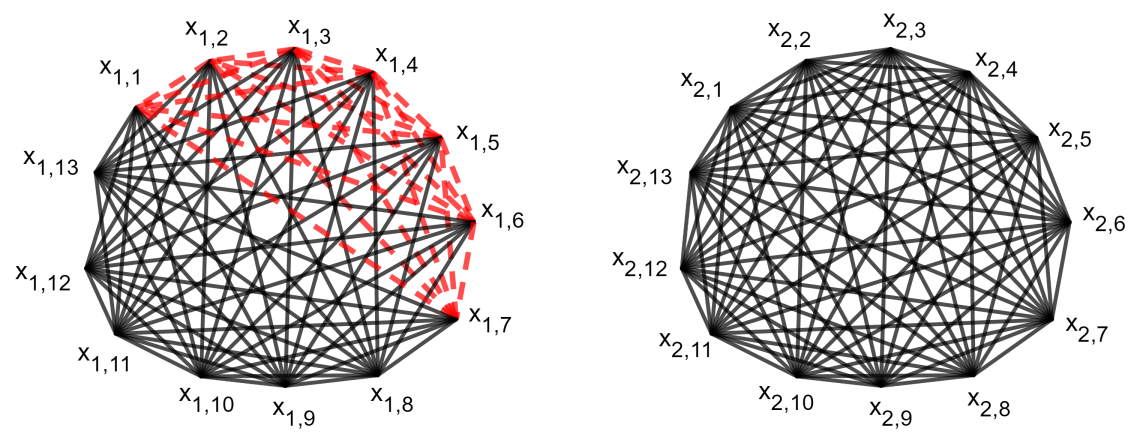

Gambar 4. $2 K_{13} \backslash\{e\} \nrightarrow\left(4 K_{2}, 2 K_{7}\right)$

$5 K_{8} \in \mathcal{R}\left(4 K_{2}, 2 K_{8}\right)$.

Bukti. Akan dibuktikan $5 K_{8} \rightarrow\left(4 K_{2}, 2 K_{8}\right)$. Pandang sebarang pewarnaan merahbiru terhadap sisi-sisi $5 K_{8}$. Pertama, andaikan terdapat $4 K_{2}$ merah, maka pembuktian selesai. Selanjutnya misalkan tidak terdapat $4 K_{2}$ merah dalam pewarnaan tersebut, maka subgraf merahnya berbentuk $3 C_{3}, 3 K_{1,7}, K_{1,7} \cup 2 C_{3}, 2 K_{1,7} \cup C_{3}$, atau $K_{7}$. Untuk kemungkinan $3 C_{3}$ jika sebarang sisi pada $2 K_{13}$ diwarnai dengan warna merah hingga membentuk $3 C_{3}$, maka sisa grafnya minimal $2 K_{8}$ yang selalu bisa diwarnai $2 K_{7}$ biru.

Selanjutnya, jika sebarang sisi pada graf $5 K_{8}$ diwarnai dengan warna merah hingga subgraf merah berbentuk $3 K_{1,7}$, maka sisa grafnya selalu memuat $2 K_{8}$ yang bisa diwarnai $2 K_{8}$ biru. Kemudian untuk kemungkinan $K_{1,7} \cup 2 C_{3}$, jika sebarang sisi diwarnai merah hingga membentuk $K_{1,7} \cup 2 C_{3}$, maka sisa grafnya minimal $2 K_{8}$ yang selalu bisa diwarnai $2 K_{8}$ biru. Untuk kemungkinan $2 K_{1,7} \cup C_{3}$, jika sebarang sisi diwarnai merah hingga membentuk $2 K_{1,7} \cup C_{3}$, sisa grafnya selalu memuat $2 K_{8}$ yang bisa diwarnai $2 K_{8}$ biru. Kemudian untuk kemungkinan terakhir $K_{7}$, jika sebarang sisi diwarnai merah hingga membentuk $K_{7}$, maka sisa grafnya $4 K_{8}$ yang selalu bisa diwarnai $2 K_{8}$ biru. Jadi, terbukti bahwa $5 K_{8} \rightarrow\left(4 K_{2}, 2 K_{8}\right)$. Berikut adalah salah satu contoh pewarnaannya.
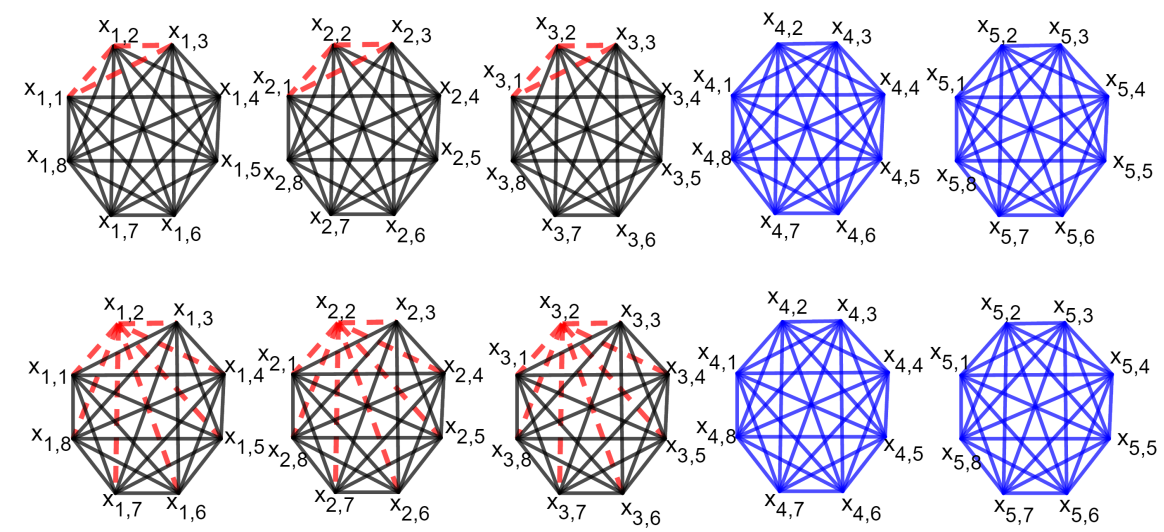

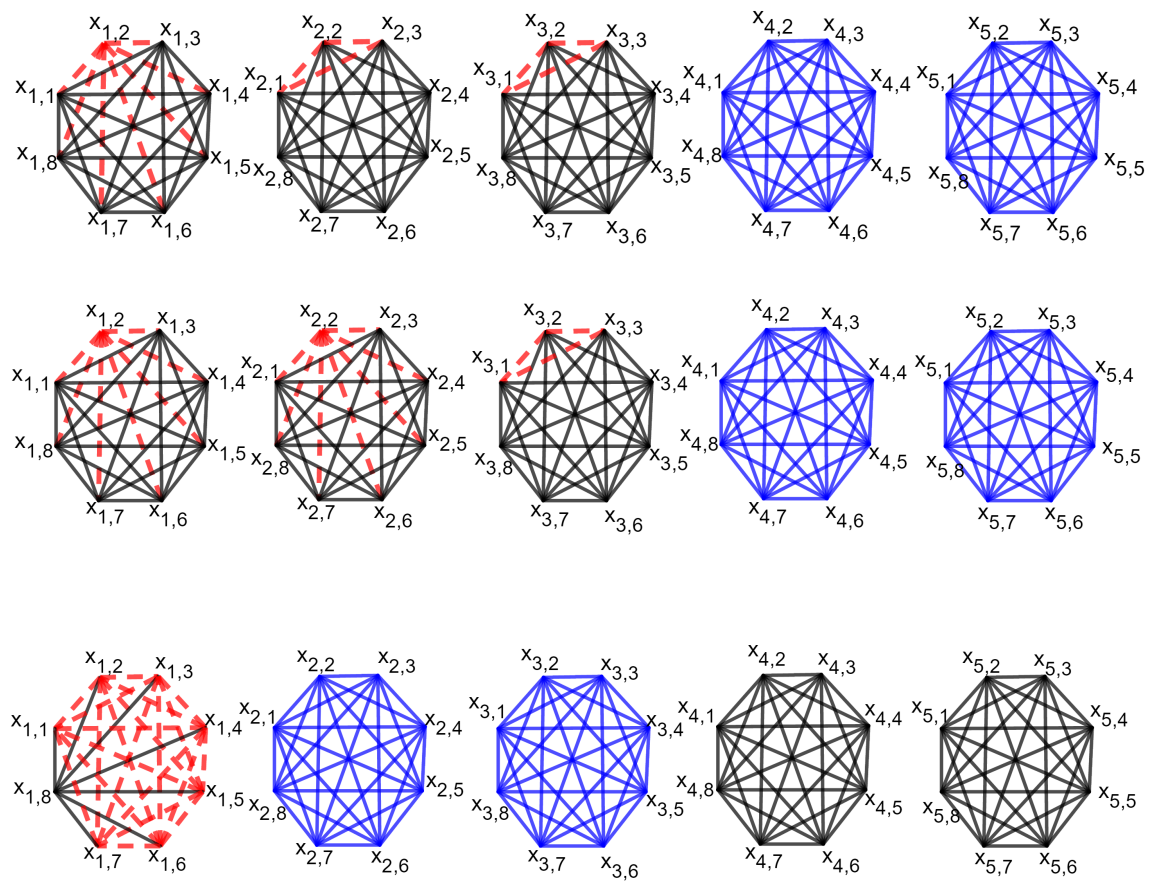

Gambar $5.5 K_{8} \rightarrow\left(4 K_{2}, 2 K_{8}\right)$

Kedua, akan ditunjukkan $5 K_{8} \backslash\{e\} \nrightarrow\left(4 K_{2}, 2 K_{8}\right) \forall e \in E\left(5 K_{8}\right)$. Saat dihapus satu sisi, lakukan pewarnaan dengan cara mewarnai $3 C_{3}$ merah pada setiap graf berbeda kecuali pada graf yang sisinya dihapus sehingga tidak diperoleh $2 K_{8}$ biru. Akibatnya terbukti bahwa $5 K_{8} \backslash\{e\} \nrightarrow\left(4 K_{2}, 2 K_{8}\right) \forall e \in E\left(5 K_{8}\right)$. Berikut adalah salah satu cara mewarnainya.

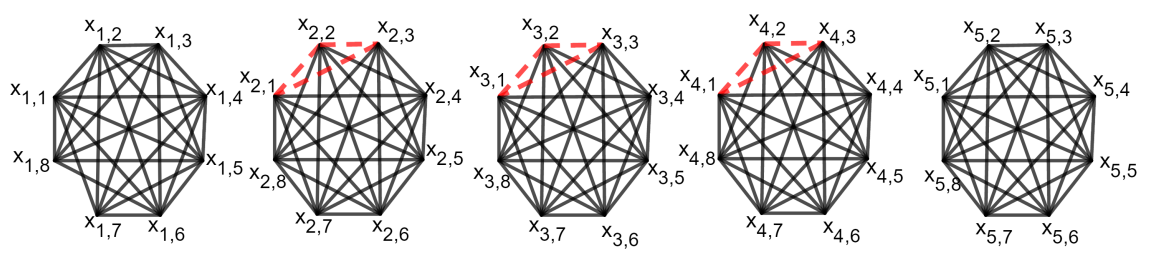

Gambar 6. $5 K_{8} \backslash\{e\} \nrightarrow\left(4 K_{2}, 2 K_{8}\right)$

\section{Kesimpulan}

Dalam makalah ini diperoleh beberapa hasil, yaitu bahwa graf $2 K_{13}$ merupakan anggota dari kelas Ramsey minimal untuk pasangan graf $4 K_{2}, 2 K_{7}$ ). Kemudian 
diperoleh bahwa graf $5 K_{8}$ adalah anggota dari kelas Ramsey minimal untuk pasangan graf $\left(4 K_{2}, 2 K_{8}\right)$.

\section{Daftar Pustaka}

[1] Bondy,J.A. dan Murty, U.S.R. 1976. Graph Theory with Application. The Macmillan Press LTD, London dan Basingstoke.

[2] Burr, S. A., Erdos, P., dan Lovasz, L. 1976. On Graph of Ramsey Type, Ars Combinatoria, 167 - 190 .

[3] Wijaya, K. , Baskoro, E. T. 2016. On Ramsey $\left(2 K_{2}, 2 H\right)$-Minimal Graphs, Springer India, J.Math, 186: 219 - 223

[4] Wijaya, K., Baskoro, E.T., Assiyatun, H., Suprijanto, D. 2016. On Ramsey $\left(m K_{2}, H\right)$-Minimal Graphs Springer Japan, J.Math, 33 , $233-243$

[5] Yulianti,L.,Nazra,A. 2018. A Note on The Ramsey Minimal Graphs for Matching versus Multiple Copies of Cycle, Electronic Journal of Graph Theory and Applications. submitted 